\title{
COVID-19 and Employment: Insights from the Sub-Saharan African Experience
}

\author{
Michael Danquah ${ }^{1} \cdot$ Simone Schotte $^{1} \cdot$ Kunal Sen $^{1,2}$
}

Published online: 28 September 2020

(c) Indian Society of Labour Economics 2020

\section{Introduction}

The COVID-19 pandemic poses risks not only for people's health but also economic well-being. While the full socio-economic consequences remain uncertain, its impact on the labour market has become a key issue of global concern. Especially low-income earners performing jobs in precarious, informal sectors of the economy without unemployment insurance, limited access to healthcare, and no back-up savings are most at risk. This implies that already disadvantaged groups will suffer disproportionately from the adverse effects. Policy makers in the Global South have responded to the adverse employment and income effects of the pandemic with a range of measures varying from cash transfers to the poor to loans to small enterprises to keep them afloat. In this note, we offer some insights on the impact of COVID-19 on employment and the policy responses that developing countries have taken, drawing from the sub-Saharan African experience. We first provide an overview of the progress of the pandemic in sub-Saharan Africa, and the mitigation and suppression measures taken by sub-Saharan African governments. We then discuss what we know so far on the employment effect of the pandemic in sub-Saharan Africa. Finally, we discuss policy responses to the pandemic, focusing on the experience of one sub-Saharan African country, Ghana.

\subsection{How have Countries in sub-Saharan Africa Responded to the COVID-19 Pandemic?}

As of 22 June 2020, according to data from the Johns Hopkins University (JHU), over 9 million COVID-19 cases have been confirmed worldwide (see Fig. 1). SubSaharan Africa (SSA) registered 230,116 cases, concentrated particularly in South Africa $(101,590)$, followed by Nigeria $(20,919)$, Ghana $(14,154)$ and Cameroon

Kunal Sen

sen@wider.unu.edu

1 UNU-WIDER, Helsinki, Finland

2 University of Manchester, Manchester, UK 


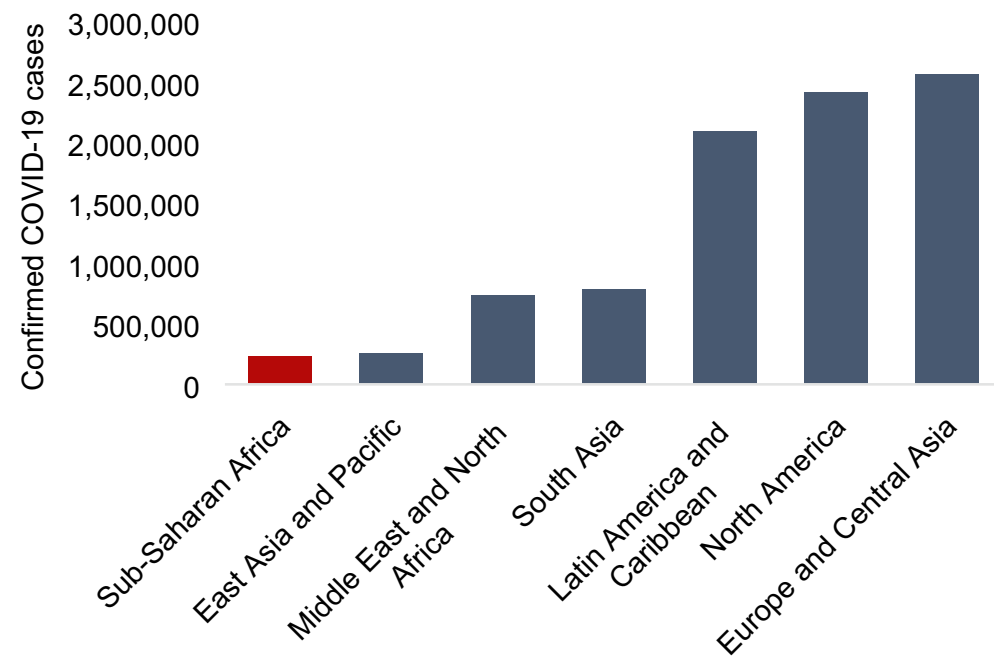

Fig. 1 Confirmed COVID-19 cases, ranking by world region, 22 June 2020. Source: Authors' own calculation and graphical presentation based on case numbers by JHU (2020)

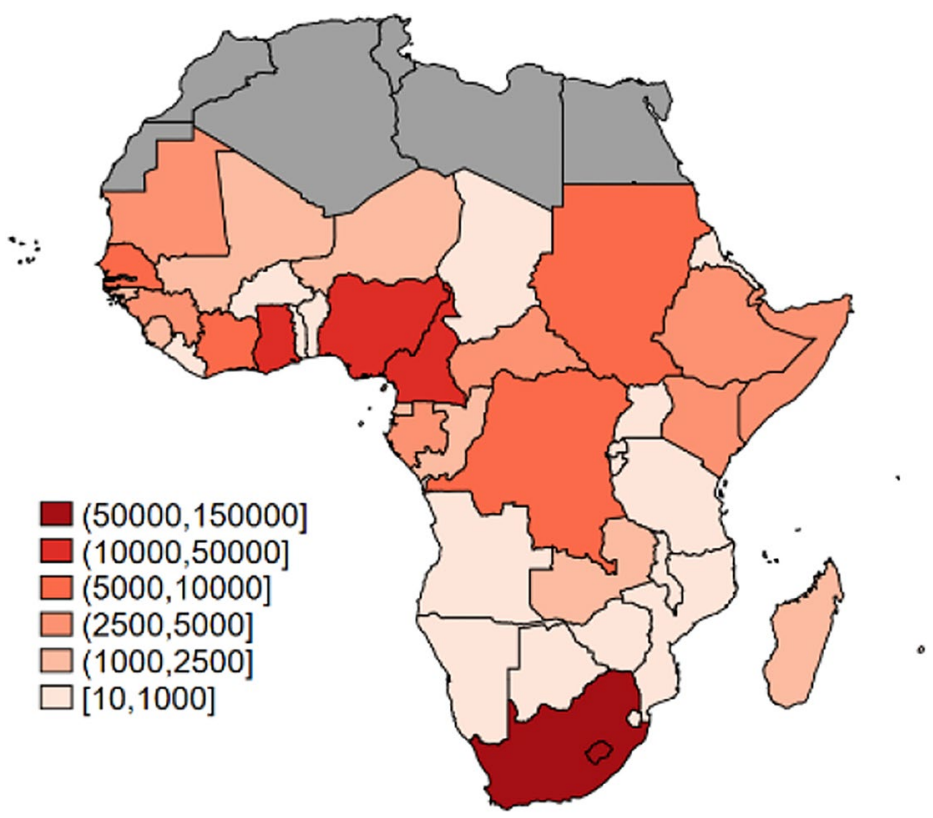

Fig. 2 Confirmed COVID-19 cases in sub-Saharan Africa, 22 June 2020. Source: Authors' own graphical presentation based on case numbers by JHU (2020) 
$(12,041)$, while around half of the countries had under 1000 confirmed cases (see Fig. 2).

In face of weak and already overwhelmed health systems, most countries across SSA responded early on with stringent government measures to contain the spread of the virus (see Fig. 3). As of 31 March 2020, according to the Oxford COVID19 Government Response Tracker (OxCGRT), out of 44 SSA countries, 95\% had closed schools for all education levels, $66 \%$ had required workplace closures (or work from home) at least for some sectors or categories of workers, $32 \%$ had closed public transport (or prohibited most citizens from using it) and $43 \%$ had adopted curfew or lockdown policies (required people not leaving house, allowing for exceptions to varying extents), along other response measures.

Globally, governments have started to gradually relax their confinement measures from May 2020 onwards (see Fig. 4). At the same time, economic support measures - mainly in the form of direct income support-have been scaled up. As of 22 June 2020, half of the countries in SSA provided some type of income support to workers as a temporary relief measure, of which the majority included transfers not only to formal employees but also to informal sector workers (OxCGRT, 2020). However, countries in SSA lag behind other world regions in terms of the economic support that is provided (see Fig. 5), and while the measures present an important step in the right direction, the effective provisions - in the majority of countries replacing less than $50 \%$ of lost salary-may not suffice to provide significant relief and secure the livelihoods of the most vulnerable people in the region (Bassier et al., 2020).

\subsection{How has COVID-19 Affected Employment in sub-Saharan Africa?}

The outbreak of the COVID-19 pandemic has posed a major disruption to economic activity across the world, including SSA. The World Bank (2020) projects that economic growth across the region will decline from $2.4 \%$ in 2019 to -2.1 to $-5.1 \%$ in 2020 . This would be the first recession that SSA has seen in 25 years, with major

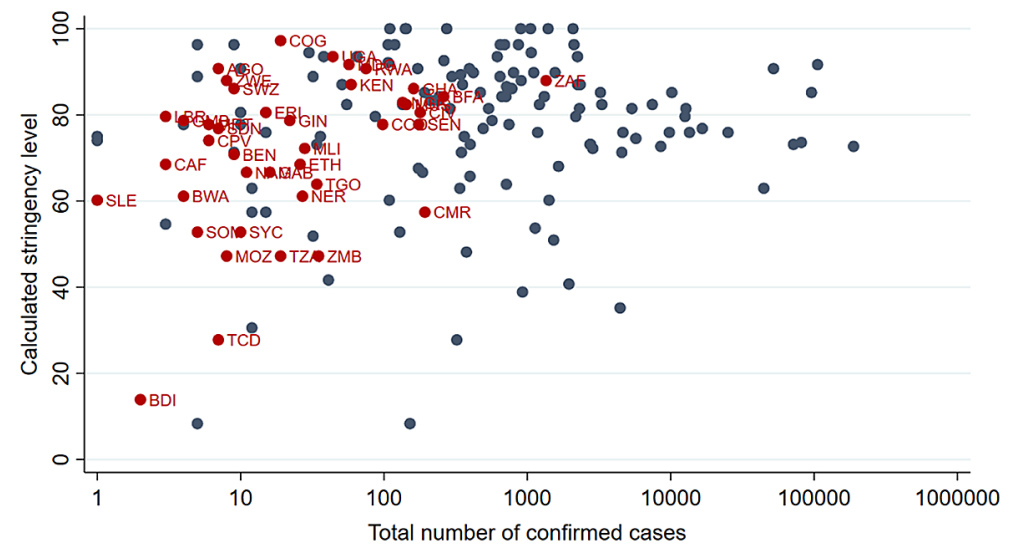

Fig. 3 Stringency of COVID-19 government responses, 31 March 2020. Source: Authors' own graphical presentation based on OxCGRT (2020) stringency index and case numbers by JHU (2020) 


\section{1-Mar-20 22-Jun-20}

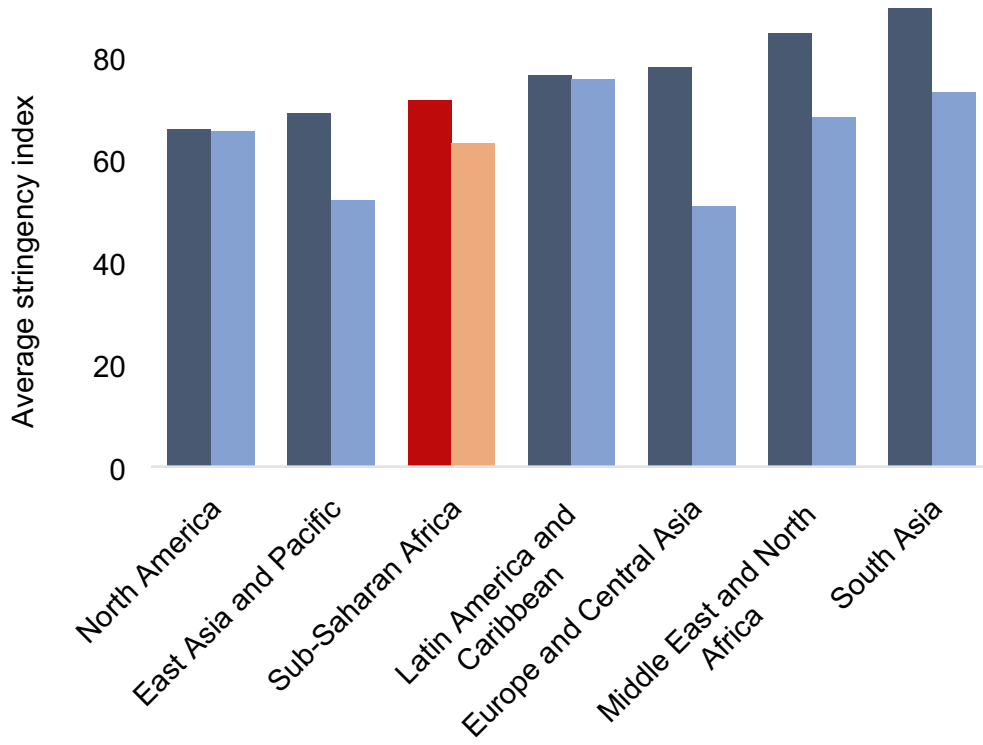

Fig. 4 Stringency of COVID-19 government responses, ranking by world region. Source: Authors' own calculation and graphical presentation based on OxCGRT (2020) stringency index

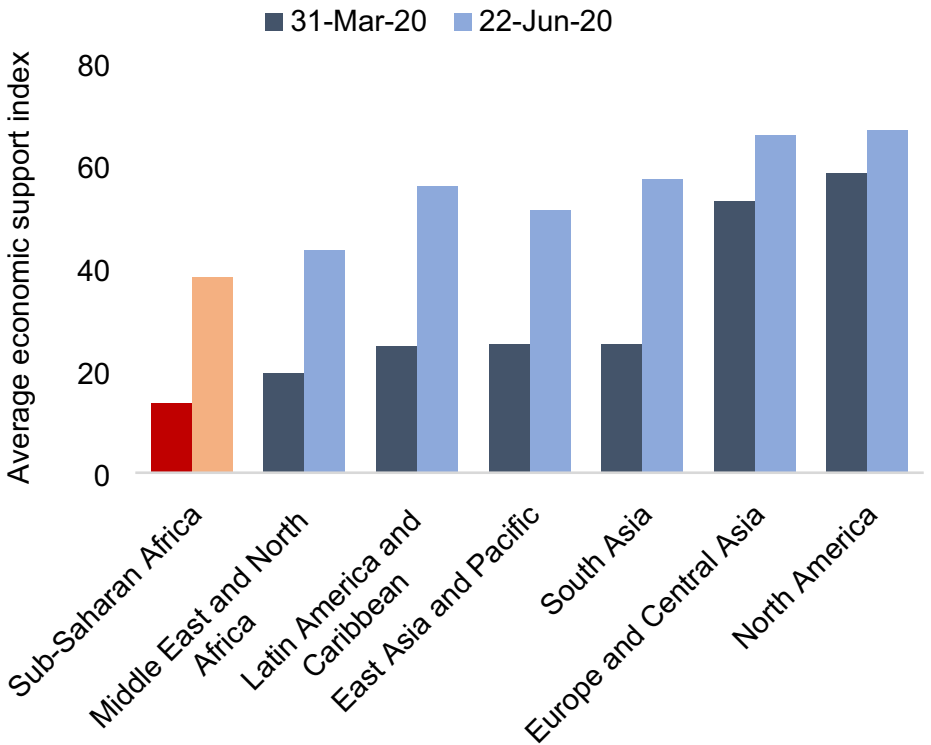

Fig. 5 COVID-19 government economic support measures, ranking by world region. Source: Authors' own calculation and graphical presentation based on OxCGRT (2020) economic support index 
impacts on poverty and food insecurity. In addition to the global drop in commodity prices and external demand from the main trading partners-including China, India, the USA, and several European countries - the adopted stringent government response measures are likely to have a devastating impact on the incomes of workers and their dependents across the region. Workplace and market closures, restrictions on mobility and the associated reduction in demand for goods and services have resulted in a slowdown in production alongside the total suspension of some activities, leading to a reduction in working hours and labour earnings. This especially affects workers in the large informal sector, accounting for $80 \%$ of all non-agricultural employment in the region (ILO, 2018).

Accordingly, for example, a recent rapid survey of businesses in Uganda suggests that lockdown measures have reduced business activity by more than half, and finds that micro- and small enterprises experienced a larger decline in activity compared to medium and large enterprises (Lakuma and Sunday. 2020). Similarly, real-time survey data collected in Senegal, Mali, and Burkina Faso suggest that on average, by the end of April, one out of four workers had lost their jobs and one out of two workers had experienced a decline in earnings. The findings furthermore indicate that informal workers are at higher risk, as they generally rely on daily sales for their earnings, lack mechanisms for collective bargaining, and tend to be in activities that are contact intensive and thus, particularly affected by the pandemic response measures-such as restaurants, tourism, small retail shops, hairdressers, and taxi drivers (Balde et al., 2020).

These labour market effects are likely to persist even when curfew and lockdown policies have been lifted, for example if customers continue to avoid crowded markets and if the economic downturn has lasting consequences for household spending. Moreover, given the nature of their work, many informal employees will remain particularly vulnerable to contracting the virus, once resuming their activities. Many of the most vulnerable are thus facing an explicit trade-off between their health and their financial survival. In addition, the pandemic response measures may also aggravate gender inequalities in employment. Not only are the smallest and most vulnerable businesses often run by women, but women will also be disproportionally affected by school and daycare closures and often leave the labour market to care for children or sick relatives.

\subsection{Policy Response to COVID-19: The Case of Ghana}

When the first two cases of COVID-19 were reported in Ghana on 12 March 2020, the country took steps to ban all public gatherings and close all schools and universities as well as the county's borders. A partial lockdown was subsequently introduced on 30 March in areas identified as 'hotspots'. This was lifted on 19 April 2020. The country's capacity to trace, test, isolate and quarantine, and treat victims of the disease was cited as one of the reasons for the decision. Nonetheless, the number of confirmed COVID-19 infections has been escalating. The update from the Ghana Health Service, as of 7 July 2020, indicates 21,968 confirmed positive cases and 129 deaths. There is therefore the need for the government to develop and deploy suitable and effective social influence strategies to persuade the population to conform to 
wearing face masks, washing hands and using hand sanitizers, and practicing social distancing, among others (Danquah and Schotte 2020).

\subsection{What Supporting Measures did the Ghanaian Government Take to Protect the Poor and Vulnerable?}

The government of Ghana rolled out the Coronavirus Alleviation Programme (CAP) to address the disruption in economic activities, the hardship of the people, and to rescue and revitalize industries. Some of the measures included (Danquah and Schotte 2020):

- an extension of the tax filing date from April to June;

- a 2 per cent reduction of interest rates by banks, effective 1 April 2020;

- the granting by the banks of a six-month moratorium of principal repayments to entities in the airline and hospitality industries, i.e. hotels, restaurants, car rentals, food vendors, taxis, and Uber operators;

- mobile money users can send up to GHф100 for free; a 100-300 per cent increase in daily transaction limits for mobile money transactions;

- the establishment of a COVID-19 fund, to be managed by an independent board of trustees and to receive contributions and donations from the public, to assist in the welfare of the needy and the vulnerable;

- a three-month tax holiday for health workers at the beginning of April 2020 and an amount of GHS80 million to pay special allowance for frontline health workers;

- fumigation of public places including markets, schools among others;

- the ministries of gender, children, and social protection, and local government and rural development, and the National Disaster Management Organization (NADMO), working with MMDCEs and faith-based organizations, to provide food (dry food packages and hot meals) for up to 400,000 individuals and homes in the affected areas of the restrictions;

- double payments to beneficiaries of the Livelihood Empowerment against Poverty (LEAP);

- government will absorb the water bills for all Ghanaians for the 3 months of April, May, and June;

- government will also fully absorb electricity bills for the poorest of the poor, defined as lifeline consumers who consume zero to $50 \mathrm{KW}$ hours a month for this period. For all other consumers, residential and commercial, government will also absorb $50 \%$ of electricity bill for this period;

- a $1.5 \%$ decrease in the policy rate and $2 \%$ in reserve requirement, respectively, by the Bank of Ghana to help improve credit to businesses. Commercial banks are to respond to these measures by the regulator and provide a $\mathrm{GH} \phi 3$ billion facility to support industry-especially in the pharmaceutical, hospitality, service, and manufacturing sectors;

- implementation of the flagship CAP business support scheme. An amount of $\mathrm{GH} \notin 1.2$ billion has been earmarked for the CAP business support scheme to be 
made available to households and businesses, particularly small and medium-scale enterprises (SMEs).

Among these measures, the flagship CAP business support scheme seems to be a major intervention due to the focus on mitigating the negative impact of COVID-19 on households and livelihoods and the support to micro, small, and medium-scale enterprises (MSMEs). Out of the $\mathrm{GH} \phi 1.2$ billion earmarked for this Programme, $\mathrm{GH} \phi 600$ million will be disbursed as soft loans to SMEs, with up to a one-year moratorium and a two-year repayment period. The rate of interest on this facility is three per cent. Additionally, selected participating banks will provide negotiated counterpart funding to the tune of $\mathrm{GH} \notin 400$ million, making, in all, $\mathrm{GH} \notin 1$ billion for disbursement under this Business Support Scheme, with the entire scheme set to attract some 180,000 beneficiaries across the country. The funds will be managed by the National Board for Small Scale Industries (NBSSI) and supervised by a loan committee. The NBSSI reports that 450,000 applicants, representing MSMEs, have registered for the fund; 66 per cent of the applicants were females and $34 \%$ are male applicants. All applicants are required to register for Tax Identification Number (TIN) with the Ghana Revenue Authority to enable them to access the COVID-19 Relief Fund. The beneficiary sectors include agri and agro businesses; manufacturing; water and sanitation; tourism and hospitality; education; food and beverages; technology; transportation; commerce and trade; healthcare and pharmaceuticals; and textiles and garments.

In order to revitalize economic activities and provide the needed support to households and livelihoods, the CAP business support scheme can target and support essential SMEs-SMEs that provide inputs and services to support other SMEs-and particularly the agricultural sector.

The policy measures taken by the government of Ghana to combat the adverse economic effects of the pandemic is representative of what other SSA governments have also done in responding to the economic crisis - a combination of cash and in kind transfers, tax breaks, and loans to small firms (see Addison et al. 2020; Ebrahim, 2020 and Were, 2020). A challenge faced by sub-Saharan African governments is that informal workers, who constitute a large proportion of the workforce in the continent, are often outside the reach of the state, making it difficult to enact the furloughing schemes that we have seen Western governments undertake. Moreover, given the precarious state of public finances in sub-Saharan Africa, more expansionary fiscal stimulus packages are difficult to implement (Addison et al., 2020). While so far the spread of COVID-19 in sub-Saharan Africa has been more limited compared to other developing regions, it remains to be seen what the overall effect of the pandemic may be on employment and livelihoods in the region, and whether the policy responses enacted so far are enough to combat the adverse effects of the pandemic on the working poor.

\section{References}

Addison, T., K. Sen and F. Tarp. 2020. COVID-19: Macroeconomic dimensions in the developing world. WIDER Working Paper No. 74/2020, Helsinki: UNU-WIDER. 
Balde, R., M. Boly, and E. Avenyo. 2020. Labour market effects of COVID-19 in sub-Saharan Africa: An informality lens from Burkina Faso, Mali and Senegal. Working Paper No. 022. Maastricht: UNU-MERIT.

Bassier, I., J. Budlender, R. Zizzamia, M. Leibbrandt, and V. Ranchhod. 2020. Locked down and locked out: Repurposing social assistance as emergency relief to informal workers. Version 2. Working Paper No. 261. Cape Town:SALDRU, UCT.

Danquah, M. and S. Schotte. 2020. COVID-19 and the socioeconomic impact in Africa: The case of Ghana. WIDER Background Note 2020/5. Helsinki: UNU-WIDER.

Ebrahim, A. 2020. COVID-19 and the socioeconomic impact in Africa: The case of South Africa. WIDER Background Note 2020/2. Helsinki: UNU-WIDER.

ILO. 2018. Women and Men in the Informal Economy: A Statistical Picture, 3rd edon.Geneva: ILO.

JHU. 2020.Data Repository for the Coronavirus Visual Dashboard operated by the Center for Systems Science and Engineering (CSSE) at Johns Hopkins University (JHU). https://github.com/CSSEG ISandData/COVID-19. Accessed 28 June 2020.

Lakuma, C.P., and N. Sunday. 2020. Africa in focus: Impact of COVID-19 on micro, small, and medium businesses in Uganda. https://www.brookings.edu/blog/africa-in-focus/2020/05/19/impact-of-covid -19-on-micro-small-and-medium-businesses-in-uganda/. Accessed 15 June 2020.

OxCGRT. 2020. The Oxford COVID-19 Government Response Tracker (OxCGRT). https://covidtrack er.bsg.ox.ac.uk/. Accessed 6 July 2020.

Were, M. 2020. COVID-19 and the socioeconomic impact in Africa: The case of Kenya. WIDER Background Note 2020/3. Helsinki: UNU-WIDER.

World Bank. 2020. Assessing the economic impact of COVID-19 and policy responses in sub-Saharan Africa. Africa's Pulse, Vol. 21. Washington, DC: The World Bank Group.

Publisher's Note Springer Nature remains neutral with regard to jurisdictional claims in published maps and institutional affiliations. 